\title{
Science for change: A survey on the normative and political dimensions of global sustainability research
}

\author{
Sandra van der $\mathrm{Hel}^{*}$ \\ Copernicus Institute of Sustainable Development, Faculty of Geosciences, Utrecht University, Princetonlaan 8a, 3584 CB Utrecht, Netherlands
}

\section{A R T I C L E I N F O}

\section{Keywords:}

Sustainability

Transformations

Knowledge

Science

Politics

Values

\begin{abstract}
A B S T R A C T
Global change and sustainability research increasingly focusses on informing and shaping societal transformations towards more sustainable futures. Doing so, researchers encounter the deeply political and normative dimensions of sustainability problems and potential solutions. This raises questions about the value-dimensions of science itself, as well as the appropriate relationship between science and politics. In this paper, these normative and political dimensions of sustainability research are explored based on a literature review and survey. The survey was completed by 284 researchers participating in the international research platform Future Earth: Research for Global Sustainability. The analysis of survey data reveals that sustainability researchers generally acknowledge the value-laden and political nature of their work, yet perspectives on what this means and how to deal with such dimensions vary. Four groups of respondents are distinguished and classified by the following broad narratives: transformative research as speaking truth to power, transformative research as political act, responsibility for rigorous science, and humility on solutions potential. Several tensions within and between these perspectives are identified, pertaining to the role of sustainability researchers in supporting societal transformations, the possibility and desirability of scientific independence and impartiality, and the appropriate relationship between science and politics. The paper concludes by pointing to the need for more explicit engagement with the normative and political dimensions of sustainability research.
\end{abstract}

\section{Introduction}

What is the appropriate relationship between science and politics? This question has triggered public and academic debates as old as the history of science itself. It surfaces yet again when we come to think about the role of science in supporting and enabling societal transformations towards sustainable futures.

Global change research has played a major role in advancing our understanding of the earth system and the major socio-environmental challenges faced by humanity today. In recent years, multiple interlinked processes have pushed the research community to shift its focus from understanding global environmental problems towards advancing solutions for sustainable futures (Belmont Forum et al., 2011; De Pryck and Wanneau, 2017; European Science Foundation, 2012; Kowarsch and Jabbour, 2017; van der Hel and Biermann, 2017). A key example is the international research platform Future Earth: Research for Global Sustainability which aims to support scientific knowledge production in pursuit of global sustainability (Future Earth, 2014; Moser, 2016). However, the ambitious objective to support societal transformations requires not only a change in research practices and the organisation of knowledge systems (Cornell et al., 2013; van der Hel, 2016), but also involves direct engagement with normative questions of what sustainable futures look like and how they can best be achieved (Kläy et al., 2015; Miller, 2013; Patterson et al., 2017; Schlaile et al., 2017; Schneidewind et al., 2016; Tschakert et al., 2016). In this context, the classic distinction between science and politics - where science attends to matters of facts and truth, whereas politics is about values, interests and power - appears misplaced (Lövbrand et al., 2015; Turnhout et al., 2016). Yet, how can and should researchers engage with the deeply normative and political dimensions of sustainability?

The answer to this question is anything but trivial. Yet, although arguably at the core of a transformative approach to sustainability, questions of values and power in sustainability research have received limited attention in the academic literature (Lövbrand et al., 2015; Turnhout et al., 2016; van Kerkhoff and Lebel, 2006; West, 2016). There are some notable exceptions, such as a study by Milkoreit et al. (2015) discussing values in resilience scholarship and by Miller (2013) discussing normative dimensions of sustainability science. However, we do not know how the vastly increasing and diverse community of sustainability researchers grapples with the normative and political

\footnotetext{
* Corresponding author.

E-mail address: s.c.vanderhel@uu.nl.
} 
dimensions of their work. Given the transformative potential of sustainability research, this lack of attention to questions of values and politics is highly surprising and reason for concern (Rosendahl et al., 2015). Therefore, this paper aims to make these pertinent dimensions explicit and explore perspectives among sustainability researchers with respect to the normative orientation of science, the relationship between science and politics, and the role of sustainability research in society.

The research question for this paper is therefore as follows: how do sustainability researchers perceive and engage with normative and political dimensions of their work? Normative dimensions, in this study, refers to the value-laden context, processes and consequences of sustainability research. Political dimensions refers to the related implicit and explicit choices that shape both sustainability research and its consequences for the way sustainability problems are understood and governed.

The paper builds on the result of a survey conducted among researchers engaged in the global research platform Future Earth: Research for Global Sustainability. The survey was informed by a literature review identifying different ways in which normative and political aspects are entangled in sustainability research (section 2). The survey approach was adopted with the aim to get an overview of different perceptions and attitudes within a diverse community of researchers. Section 3 introduces the research design, focus of the survey and method of data collection and analysis. Combining quantitative and qualitative analysis, four distinct clusters of respondents are identified reflecting different perceptions on sustainability research (presented in section 4). The discussion (section 5) elaborates on several core tensions and the conclusion (section 6) encourages more explicit engagement with the normative and political dimensions of sustainability research.

\section{Theoretical context}

\subsection{Action, solutions and societal change in sustainability research}

Global change and sustainability research have become increasingly concerned with action, solutions and societal change (Future Earth, 2014; Lahsen, 2016; van Kerkhoff and Lebel, 2006; West, 2016). Global change and sustainability research build on a long tradition of describing and explaining major earth system transformations and societal change processes. Yet, researchers today are increasingly challenged to advance the resolution of pressing sustainability problems and inform transformations towards sustainability (Berker and Bharathi, 2012; De Pryck and Wanneau, 2017; Miller et al., 2014; Wiek et al., 2012). As such, the focus of sustainability research is, at least in rhetoric, shifting from research on sustainability to research for sustainability (Jerneck et al., 2011; Miller, 2013; Schneidewind et al., 2016). This shift in focus is accompanied with the claim that the responsibility of researchers should be extended from producing rigorous knowledge to the implementation of knowledge in society (Fazey et al., 2014; Mauser et al., 2013). In that sense, science is recognized as an active process of intervention with the ability to inform and facilitate societal transformations in order to avoid catastrophic environmental change (Fazey et al., 2018).

The turn towards transformative and solutions-oriented sustainability research does not stand on its own. Rather, this development should be understood in a broader perspective of debates about the changing role of science in society. Notions of Mode-2 knowledge production (Nowotny et al., 2003), transdisciplinarity (e.g. Klein, 2014) and post-normal sciences (Funtowicz and Ravetz, 1993) are influential descriptions of changes in science towards a system where knowledge production is more socially robust, increasingly interdisciplinary and co-produced with societal actors. Such perspectives on scientific knowledge production, however, stands in tensions with historically developed norms of science as objective, universal, value-free, and independent from contexts. The boundary between universal science (objective, autonomous, disinterested) and societal context (values, norms, interests) drawn by such Mertonian norms of science is difficult to uphold for knowledge production that directly engages with complex, value-laden and urgent real-word issues (Caniglia et al., 2017; Funtowicz and Ravetz, 1993; Lang et al., 2012).

Relating to these broader debates, scholars of sustainability science have argued that a transformative and solutions-oriented approach to sustainability research requires that researchers 'step out of their academic comfort zone' of objectivity and independence (Miller et al., 2014; Wittmayer and Schäpke, 2014). Instead, researchers should directly and reflexively engage with the normative and political dimensions of their work. In this context, Fazey et al. (2018) argue that sustainability researchers "need to be able to take into account normative aspects, inequalities, politics and power, and work more directly across the interface of science and practice" (Fazey et al., 2018, p. 55). At the same time, concerns exist about the ambitious objectives and promises contained in the narrative of transformative and solutions-oriented sustainability research. In particular, scholars have identified the need to be humble about the capacity of science to provide solutions for complex societal challenges (Kläy et al., 2015; Lövbrand et al., 2015; Stirling, 2014), and warn about the dangers of solutionism, where every problems appears to have a single solution and the role of values and power is ignored (Strohschneider, 2014). Moreover, some scholars have expressed concerns that the credibility and authority of science could be undermined by its direct engagement with value-laden discussions and political debates (Lacey et al., 2015; Milkoreit et al., 2015; Clark et al., 2016).

\subsection{Normative and political dimensions of sustainability research}

The transformative and solutions-oriented focus of sustainability research thus forgrounds the importance to take into account normative and political concerns. Yet what are the different ways in which values and politics are entangled in sustainability research? Drawing on sustainability science, science and technology studies, science and policy studies and environmental governance literature, I distinguish four

Table 1

Normative and political dimensions of sustainability research.

\begin{tabular}{|c|c|c|}
\hline Dimension & Key points & Relevance for sustainability research(ers) \\
\hline $\begin{array}{l}\text { I Normative and political context of } \\
\text { sustainability research }\end{array}$ & $\begin{array}{l}\text { - Sustainability as a normative aspiration } \\
\text { - Context of competing interests and power asymmetries }\end{array}$ & $\begin{array}{l}\text { - Values and politics as part of problem identification } \\
\text { and analysis } \\
\text { - Relationship between research and political context }\end{array}$ \\
\hline II Standpoint and values of researcher & $\begin{array}{l}\text { - Knowledge claims are socially situated and partial } \\
\text { - Standpoint of researcher influences research process and } \\
\text { outcomes }\end{array}$ & $\begin{array}{l}\text { - Awareness of epistemic and normative positionality } \\
\text { - Importance of transparency and reflexivity }\end{array}$ \\
\hline III Power structures and asymmetries & $\begin{array}{l}\text { - Power asymmetries in society affect scientific knowledge } \\
\text { production }\end{array}$ & $\begin{array}{l}\text { - Influence on research agendas and outcomes } \\
\text { - Risk of reproducing dominant discourses }\end{array}$ \\
\hline IV (Epistemic) power of scientific knowledge & $\begin{array}{l}\text { - Science influences societal and political debates in } \\
\text { complex and important ways }\end{array}$ & $\begin{array}{l}\text { - Responsibility of researchers } \\
\text { - Role in political debates }\end{array}$ \\
\hline
\end{tabular}


normative and political dimension of sustainability research. Below I briefly discuss each dimension and its relevance fos sustainability research and researchers (see Table 1 for an overview).

First, sustainability research is set in a normative and political context. Although sustainability is well accepted in its general meaning, it is often strongly disputed when it comes to concrete terms and implementation. The idea of sustainability includes fundamentally normative assertion concerning environmental and social values, conceptions of justice and ideals of desirable futures (Anderson et al., 2016). Moreover, transformations towards sustainability take place in a context of competing interests and power asymmetries (O'Brien, 2011; Patterson et al., 2016). Scholars have argued that sustainability researchers should take this normative and political context into account when addressing complex problems of sustainability and identifying possible solutions (Miller et al., 2014; Pohl et al., 2010; Wiek and Kay, 2015; Fazey et al., 2018). Yet, as previous studies have pointed out, researchers may prefer different ways to engage with political debates and societal controversy (Turnhout et al., 2008) and find different ways to balance normative aspirations with epistemic concerns (Milkoreit et al., 2015; Miller, 2013).

Second, as social studies of science have long held, the socially situated and normative position of the researcher and her researchinfluences the research process and outcomes, regardless of whether researchers are aware of possible biases and make them explicit (Milkoreit et al., 2015; Rosendahl et al., 2015; West, 2016). While transparency about values and assumptions is a widely shared norm, it is often argued that sustainability researchers need to go further and take a reflexive stance with respect to personal and collective valuecommitments and the way in which these affect knowledge claims (Mukhtarov, 2016; Pasgaard et al., 2017; Popa et al., 2014; Wittmayer and Schäpke, 2014). Such an attitude increases researchers' awareness of their epistemic and normative positionality, which not only shape research priorities and questions but also affect which research approaches will be taken and which stakeholders will be involved (Scholz, 2017; Wittmayer and Schäpke, 2014). At the same time, the Enlightenment ideal of science as a value-neutral description of reality still appears to receive broad support. In this context, scientific objectivity may be perceived as a proxy for political neutrality, whereas subjectivity in the scientific enterprise is dismissed as practicing advocacy rather than science (Milkoreit et al., 2015; Miller, 2013).

Third, normative and political concerns are raised with respect to the external factors shaping sustainability research. Through funding and other incentive structures, influential societal actors may disproportionally influence scientific agendas and outcomes (Österblom et al., 2017; Tschakert et al., 2016; van der Hel, 2016; van Kerkhoff and Lebel, 2015). This is not necessarily an intentional process, but rather a consequence of the specific context in which sustainability research takes place. However, for socially relevant and urgent issues of global change and sustainability, the allocation of resources and focus of research can have important societal consequences (Fazey et al., 2018). Given the risk of science uncritically reproducing dominant discourses, it is argued that sustainability researchers "must be willing, and able, to stir things up by actively mobilizing counter-discourses and by articulating values and options that do not fit with the hegemonic discourse" (Wesselink et al., 2013). This requires structural orientation to the ways in which policy discourses and power structures affect scientific research, rather than assuming a power-free and policy neutral research context (Tschakert et al., 2016; Wesselink et al., 2013; Fazey et al., 2018).

Finally, fourth, the (epistemic) power of scientific knowledge affects how we understand and act upon the world around us (Lövbrand et al., 2009; Turnhout et al., 2016; Wesselink et al., 2013). Several studies show how science influences societal and political debates in complex and important ways, for example by constructing categories such as ecosystem services that hence become amenable for governance (Turnhout et al., 2007) or by conditioning an imaginary of climate change as a global-scale environmental problem in need of effective governance (Demeritt, 2001; Miller and Edwards, 2001). Science supports and helps shape certain problem framings and policy discourses, attracts particular target audiences, and may privilege certain solutions over others (Turnhout et al., 2016; Wesselink et al., 2013). In this context, scholars have identified sustainability researchers as political actors that are engaged in the process of changing and shaping society (Jahn et al., 2012; Turnhout et al., 2016; Wittmayer and Schäpke, 2014).

To sum up, normative and political aspects are entangled in sustainability research through the value-laden context of sustainability research, the standpoint and value of researchers, the societal structures and power asymmetries that shape the research landscape, and the epistemic power of science. These dimensions do not represent strictly separated categories but rather interlinked aspects of scientific knowledge production for sustainability. Here, they are used heuristically as a way to capture different aspects of sustainability research and structure the empirical analysis.

\section{Materials and methods}

The normative and political dimensions of sustainability research distinguished above are further explored through a survey of sustainability researchers. The survey approach was adopted in order to provide insight into different patterns of thought across the community, and, by doing so, give an empirical context to, thus far, largely theoretical and conceptual debates.

\subsection{Case study: Future Earth}

The context for the survey is the global research platform Future Earth: Research for Global Sustainability. This research platform, launched in 2012, brings together researchers from multiple scientific disciplines and different countries globally around the common theme of global sustainability. Future Earth aims to support interdisciplinary, coproduced and solutions-oriented sustainability research. The network consists of multiple scientific projects - ranging from atmospheric chemistry to land-use change to environmental governance - and Knowledge Action Networks, intended to strengthen the interaction between scientific and social actors and inform solutions for complex societal issues. Given the ambitious objective of Future Earth to inform and shape transformations towards global sustainability, questions about normative and political dimensions of sustainability research touch upon its core.

\subsection{Survey design}

The survey included statements related to the ideal of transformative and solutions-oriented research for sustainability, as well as statements for each of the four normative and political dimensions of sustainability research distinguished through the literature review (see Tables 1 and 3). The survey statements reflect different ways in which researchers perceive and believe they should act with respect to the normative and political dimensions of their work. The set of statements includes items reflecting individual believes and attitudes as well as collective responsibilities. This diversity of statements was chosen in order to capture a wide range of views. Formulation of the statements was informed by earlier surveys addressing related topics (Hoppe, 2009; Rudd, 2015; Spruijt et al., 2016). The statements were tested during three round table discussions at a Future Earth meeting in Bern, Switzerland (June 2016) and adjusted based on feedback provided by the participants.

Survey respondents were asked to indicate their (dis)agreement with these statement on a five-point Likert scale (ranging from strongly disagree to strongly agree). At the end of each set of statements, respondents were asked to provide written comments. In addition, the 
survey included background questions, such as age, discipline, career level and region of residence ${ }^{1}$.

\subsection{Survey distribution and response}

A request to participate in the survey was posted on Future Earth's web page, and the survey was distributed through Future Earth's social media channels. In addition, the survey was circulated by the various research projects, regional networks and other initiatives operating under the umbrella of Future Earth. Responses were collected during October and November 2016 using SurveyMonkey software.

A total of 284 respondents completed the survey. The sample is selfselected and statistically non-representative of the population of researchers engaged in Future Earth ${ }^{2}$. Nevertheless, a diverse set of respondents was reached, reflecting different disciplinary perspective on sustainability research, as well as different geographical regions and career-levels. From the 43 active projects operating under the umbrella of Future Earth at the time of the survey, 39 projects were represented in the survey sample by at least 2 respondents. The geographical composition of the sample, including the dominance of researchers from the Global North, is roughly similar to the geographical spread of researchers participating in Future Earth's online platform at the time of research ${ }^{3}$. Characteristics of the sample are provided in Table 2.

\subsection{Analysis of survey data}

The data analysis combines quantitative analysis of survey responses with a qualitative analysis of written comments. The quantitative part of the analysis consisted of a cluster analysis of the response to 24 statements on transformative research and its normative and political dimensions. Cluster analysis is a well-established method in the social sciences to classify observations into groups and has been used across a wide variety of fields (Barr et al., 2011; De Witt et al., 2016; Feola and Nunes, 2014; Graham et al., 2014; Reyes-García et al., 2014; Turner et al., 2014). The aim of the cluster analysis was to identify similarities in response patterns, which can be more insightful than analysing responses to each statement separately. The validity of a cluster analysis depends largely on the survey items used as input for the analysis. The selected items should be sufficiently comprehensive and diverse to capture the various dimensions of the investigated phenomenon. The set of 24 statements used in this analysis was, as explained above, derived through a literature review with the aim to capture different normative and political dimensions of sustainability research. Moreover, the statements were formulated in such a way as to allow for a broad variety of responses.

The cluster analysis consisted of several steps. First, a hierarchical clustering was conducted using Ward's approach with a squared Euclidean distance measure. Based on an initial review of the results, the four cluster solution was selected for further analysis as it produced clearly distinguishable groups of respondents with distinct responses to the selected statements. Second, the cluster solution was optimized by using the cluster means from the hierarchical clustering as input for a K-

\footnotetext{
${ }^{1}$ The survey included several other questions about preferred role and stakeholder interaction that were not included in this study.

2 The exact composition of the community of researchers engaged in Future Earth is unclear, making it impossible to determine whether the researchers reached with this survey are representative of the network. In some of its external communication, Future Earth refers to a community of 50.000 researchers. However, no comprehensive database of this community exists. Probably a better reference is formed by the 2778 followers on Facebook, 2700 followers on Twitter, and $3000+$ individuals signed up to Future Earth online platform called the 'Open Network' (Future Earth annual report 2016-17)

${ }^{3}$ For an overview of the current geographical distribution of researchers engaged in the Future Earth's online platform, see the 'Open Network' map which is available here: https://network.futureearth.org/home
}

Table 2

Survey response.

\begin{tabular}{ll} 
Gender & \\
Male & 133 \\
Female & 131 \\
No answer & 20 \\
Career level & \\
PhD/junior researcher & 94 \\
Post-doctoral researcher & 25 \\
Senior researcher & 77 \\
Full professor & 38 \\
Other & 41 \\
No answer & 9 \\
Discipline & \\
Natural sciences & 70 \\
Social sciences & 77 \\
Interdisciplinary sciences & 91 \\
Professional or applied sciences & 16 \\
Other & 20 \\
No answer & 10 \\
Region of residence & \\
Europe & 118 \\
North America & 56 \\
Latin America and Caribbean & 18 \\
Asia & 29 \\
Africa & 28 \\
Oceania & 29 \\
No answer & 29 \\
Total & 29 \\
\hline
\end{tabular}

means cluster analysis. This combination of hierarchical and K-mean cluster methods minimizes within cluster variance while maximizing variance between clusters (see Ramm et al., 2017 and De Witt et al., 2016). The third step was to distinguish the characteristics of the respondents in each cluster, and identify significant differences between the clusters using Chi-square tests. The analysis was conducted using SPSS 24 for Windows.

In addition, written responses to the open questions in the survey were analysed to enrich the cluster interpretation and provide additional insights on the way researchers perceive and experience the normative and political dimensions of their work. A total of 312 written comments were received, provided by 143 out of 284 respondents. Written responses were first organized per cluster and then analysed thematically using the qualitative data analysis software NVivo 11 for Windows. The coding scheme was based on the literature review and included relevant sub-codes for each of the identified dimensions (Table 1). The results of the coding process informed the cluster interpretation. Additionally, three core tensions were identified with respect to the role of sustainability researchers in societal transformations, the possibility and desirability of scientific independence and impartiality, and the appropriate relationship between science and politics (discussed in Section 5).

\section{Results}

Overall, researchers engaged in Future Earth and participating in the survey support the objective of transformative research for sustainable futures. Most respondents strongly agree (42\%) or agree (43\%) that scientists should actively seek solutions for sustainability challenges through their research. Likewise, most respondents strongly agree $(44 \%)$ or agree $(43 \%)$ that it is their responsibility as a researcher to contribute to societal change towards sustainability. Less than $10 \%$ of respondents disagreed with either or both of these statements. Responses are more diverse when it comes to perspectives on the normative and political dimensions of transformative sustainability research. In particular, respondents hold different views with respect to the way researchers should engage with political debates and societal controversies around sustainability. Although most respondents 
Table 3

Overview of survey statements and responses per statement.

\begin{tabular}{|c|c|c|c|c|c|c|c|}
\hline \multirow{2}{*}{\multicolumn{2}{|c|}{ Statements }} & \multirow[b]{2}{*}{ Reference } & \multicolumn{5}{|c|}{ Response $^{\mathrm{a}}(\%)$} \\
\hline & & & 1 & 2 & 3 & 4 & 5 \\
\hline \multicolumn{8}{|c|}{ Statements on transformative sustainability research } \\
\hline 1 & It is my responsibility as a scientist to contribute to societal change towards sustainability & Societal change & 2,5 & 3,2 & 9,2 & 41,5 & 43,6 \\
\hline 2 & Through my research, I actively seek solutions for sustainability challenges & Solutions & 1,8 & 3,9 & 9,3 & 43,1 & 42,0 \\
\hline 3 & $\begin{array}{l}\text { As scientists, we need to be humble about the capacity of our research to provide solutions for sustainability } \\
\text { challenges }\end{array}$ & Humility & 3,2 & 12,1 & 13,2 & 42,5 & 28,9 \\
\hline 4 & $\begin{array}{l}\text { My job as a scientist does not stop at producing rigorous science, it also includes the implementation of } \\
\text { knowledge in society }\end{array}$ & Implementation & 1,4 & 8,6 & 13,3 & 46,6 & 30,1 \\
\hline \multicolumn{8}{|c|}{ Statements on normative and political dimensions of sustainability research ${ }^{\mathrm{b}}$} \\
\hline \multicolumn{8}{|c|}{ I. Normative and political context of sustainability research } \\
\hline 5 & When addressing complex problems of sustainability, science cannot isolate itself from politics & Isolate from politics & 0,4 & 9,6 & 10,0 & 46,3 & 33,8 \\
\hline 6 & As a scientist you risk producing irrelevant knowledge if you ignore the political context of your research & Irrelevant knowledge & 4,9 & 19,8 & 15,2 & 37,5 & 22,6 \\
\hline 7 & In a situation of societal controversy, it is impossible for scientists to take an independent position & Independent position & 6,1 & 33,1 & 22,7 & 32,4 & 5,8 \\
\hline 8 & Science's job is to clarify the facts based on which political decisions can be made & Clarify the facts & 5,0 & 11,0 & 19,1 & 44,3 & 20,6 \\
\hline & Good scientific solutions are too often spoiled by politics & Spoiled by politics & 1,8 & 16,8 & 27,6 & 35,5 & 18,3 \\
\hline \multicolumn{8}{|c|}{ II. Standpoint and values of researcher } \\
\hline 10 & $\begin{array}{l}\text { In the value-laden context of sustainability research, scientists need to be open about their own values and } \\
\text { interests }\end{array}$ & Transparency & 1,1 & 2,5 & 11,3 & 52,7 & 32,4 \\
\hline 11 & The research process is never free from personal biases & Biases & 1,8 & 7,2 & 10,8 & 50,7 & 29,5 \\
\hline 12 & My personal values do not affect the way I conduct my research & Values & 18,3 & 42,8 & 18,7 & 16,9 & 3,2 \\
\hline 13 & I find it important to keep an impartial position on the issues I address in my research & Impartiality & 1,1 & 18,2 & 24,4 & 43,6 & 12,7 \\
\hline 14 & I do not advocate specific societal changes, as this would undermine my credibility as a scientist & Credibility & 20,4 & 48,9 & 17,1 & 12,1 & 1,4 \\
\hline \multicolumn{8}{|c|}{ III. Power structures and asymmetries } \\
\hline 15 & Scientists must be careful not to reaffirm dominant world views & World views & 0,4 & 8,8 & 34,9 & 36,4 & 19,5 \\
\hline 16 & To get my research funded, I make sure that it aligns with current policy agendas & Public funding & 5,9 & 18,6 & 37,2 & 30,5 & 7,8 \\
\hline 17 & $\begin{array}{l}\text { I am hesitant to accept funding from private funding agencies as this may harm my independent position as a } \\
\text { scientist }\end{array}$ & Private funding & 5,2 & 28,1 & 39,6 & 20,4 & 6,7 \\
\hline 18 & $\begin{array}{l}\text { I believe it is my responsibility as a scientist to encourage the participation of marginal societal groups in my } \\
\text { research }\end{array}$ & Marginal societal groups & 3,3 & 10,3 & 23,6 & 43,5 & 19,2 \\
\hline 19 & To make a difference in society, I believe it is important to work together with influential societal actors & Influential societal actors & 0,4 & 3,3 & 17,2 & 58,2 & 20,9 \\
\hline \multicolumn{8}{|c|}{ IV. (Epistemic) power of scientific knowledge } \\
\hline 20 & Scientists are political actors engaged in the process of shaping and changing society & Political actors & 3,5 & 13,1 & 21,6 & 43,5 & 18,4 \\
\hline 21 & Science's ability to speak truth to power makes it a valuable factor in the transition to sustainability & Speaking truth to power & 2,5 & 7,4 & 12,4 & 49,3 & 28,4 \\
\hline 22 & In my work as a scientist, I aim to be policy relevant but not prescriptive & Relevant not prescriptive & 1,4 & 13,5 & 22,8 & 47,3 & 14,9 \\
\hline 23 & $\begin{array}{l}\text { Only knowledge produced by the scientific method can provide an objective perspective on the situation at } \\
\text { hand }\end{array}$ & Scientific method & 16,7 & 33,7 & 21,9 & 22,6 & 5,2 \\
\hline 24 & The value of lay and practitioner knowledge in addressing sustainability problems is often underestimated & Other types of knowledge & 0,0 & 2,2 & 15,9 & 48,9 & 33,0 \\
\hline
\end{tabular}

a Response: strongly disagree (1), disagree (2), neither agree nor disagree (3), agree (4), strongly agree (5).

b Statements organized by dimensions identified through the literature review.

recognised the importance of being transparent about their values and interests, ideas about the possibility and desirability of impartiality differed. Overall, responses to the statements concerning external power structures were mostly moderate. While responses to the statements on the (epistemic) power of scientific knowledge again reflect diverse perspectives (see Table 3 for an overview of the responses per statement).

\subsection{Cluster solution}

Based on the cluster analysis, four groups of respondents are identified (see Fig. 1). The chosen method assigns each respondent to one of the four clusters based on the similarity of responses across the 24 statements. The identified clusters are discussed in turn below and illustrated with quotes derived from the open questions in the survey.

\subsubsection{Cluster 1: Transformative research by speaking truth to power}

This first cluster is the largest of the four identified clusters with 104 respondents. Researchers in this cluster strongly agree with the objectives of transformative sustainability research. That is, respondents aim to contribute to societal change, seek solutions for sustainability challenges and contribute to the implementation of scientific knowledge in society. In particular, respondents point to the need for scientists to take an active role in providing the scientific knowledge base for political decision-making.

[I]t's important to understand one's limitations, but there is also a problem of scientists not wanting to speak out about general problems because they only consider themselves knowing a bit of it. Most times a bit of scientific knowledge, although not all-encompassing, is better than policy without any fact base at all.

While most respondents in this cluster agree that researchers in sustainability need to be transparent about their personal values and interests, they also find it important to seek an impartial position. In particular, respondents appear to make a distinction between the way normative decisions affect their selection of research topics, and the way normative aspects affect the research process. While respondents recognize the value-laden decisions that shape research agendas, the research process-in the view of respondents-should be free from normative aspects to the greatest extent possible.

I design research projects in response to the information needs of others, but the methods I use and results I report are unaffected by external factors.

[I] believe that it is possible to be rigorous in not allowing bias to taint your work, while maintaining strong personal views and opinions.

There is strong overall agreement that science's ability to speak truth to power makes it a valuable factor in the transition to sustainability. Most respondents agree that science should be policy relevant but not prescriptive.

I am doing research to have credibility in the political arena. I think it's important to speak truth to power, and as a part of that [change the] system from the inside. I hope to use my research to affect 


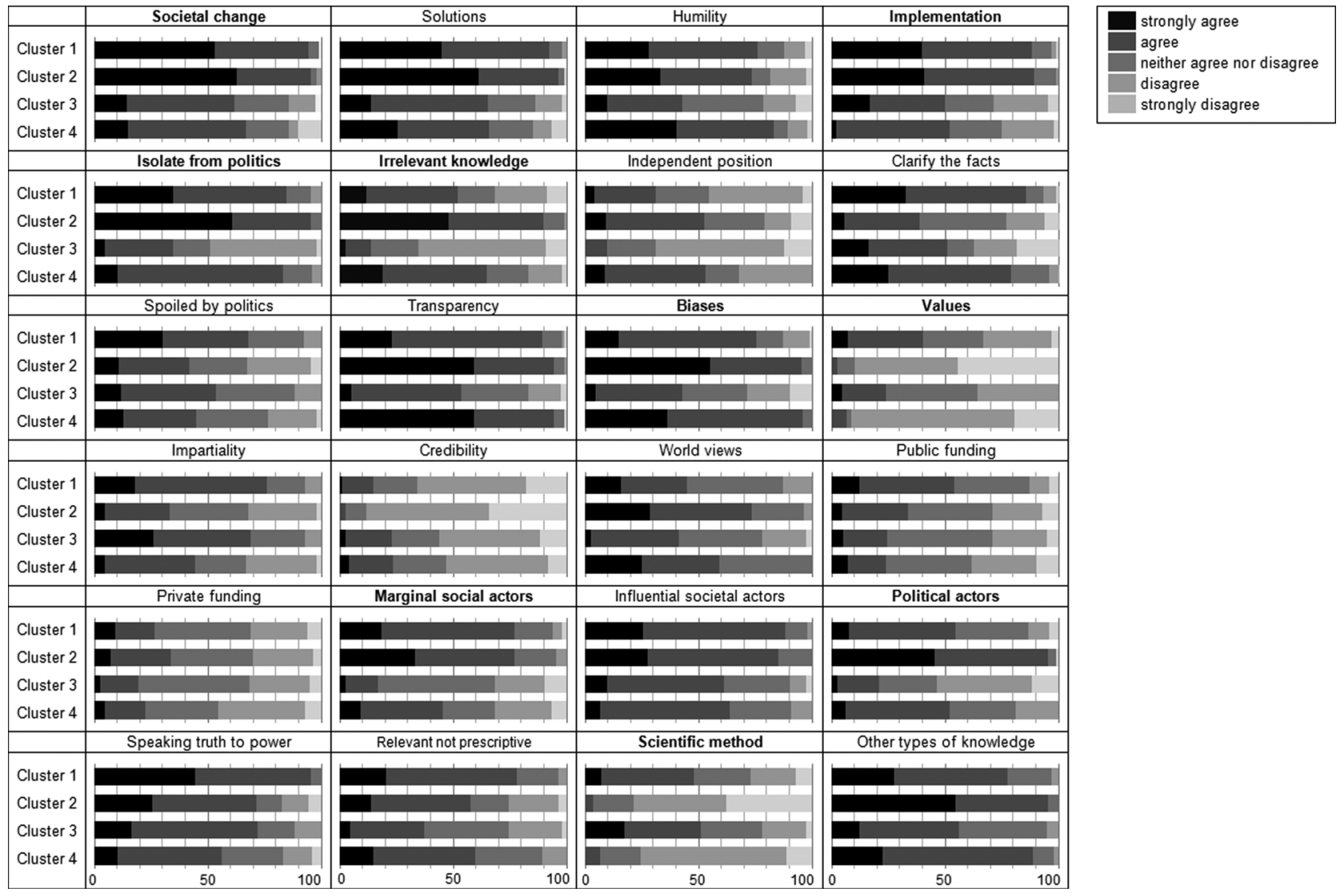

Fig. 1. Response to statements by cluster.

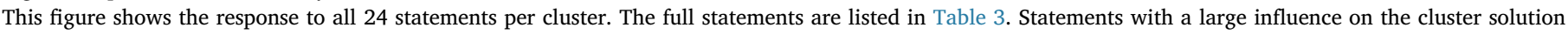
( $\mathrm{F}>25)$ are marked in bold.

political change.

I specifically try to remain policy relevant and not policy prescriptive. For example, if we (we broadly, a city, nation or the world) are aiming to achieve something like the $2^{\circ}$ target, there are any number of ways that this could be achieved [...] as a scientist I can provide information as to the implications of any of these options, but which one is chosen is a matter of politics.

Finally, working with (influential) societal actors is perceived as an important aspect of transformative research for sustainability. Respondents point out that working with societal actors establishes trust, which is considered of particular importance when addressing value-laden issues of sustainability. Moreover, respondents in this cluster focus on working with actors that have an influence "on-theground" in order to enhance the impact of sustainability research in society.

Overall, researchers in this cluster, while acknowledging the social, normative and political dimensions of sustainability, tend to draw a line between the domains of science and politics. This is reflected in the societal role they see for themselves ('speaking truth to power') and the importance that is placed on scientific norms of independence and impartiality.

\subsubsection{Cluster 2: Transformative research as political act}

Similar to cluster one, the 88 respondents in this cluster strongly agree with the objectives of transformative sustainability research. They also agree that science cannot isolate from politics when addressing sustainability issues, and worry that science will produce irrelevant knowledge if the political context of research is ignored. However, unlike respondents in the first cluster, respondents in this cluster emphasize the political nature of scientific knowledge production.
Science has vested interests and ideologies just the same as any aspect of society, including politics. It is not possible to draw distinct lines between where science and policy start and finish, it is blurred and fluid.

Once you step into arenas where you are engaging with social or political change as a scientist you are engaging with politics. [It is] better to acknowledge [that] than to pretend otherwise.

Whereas respondents in the first cluster were generally concerned about the way values influence their work and said to strive towards neutrality and impartiality, researchers in this second cluster commented that impartiality is not only impossible to achieve, but also undesirable in the context of urgent sustainability problems. Rather than striving for impartiality, researchers should be stepping up and making a statement against unsustainable practices and systems. Respondents stressed the need to build such actions on rigorous science, but are not generally concerned that advocating specific societal changes would affect their scientific credibility.

Sustainability in the face of catastrophic environmental change [is] not an impartial issue if one values the present and future of humanity on Earth. To me, avoiding discussion of values would be biasing the research!

The social consequences of sustainability research are so great it is impossible to be completely detached, and nor should we be. At the same time, it is important to ensure (and to demonstrate) that the actual research is conducted rigorously. Openness and transparency [are] important here.

More than for other clusters, researchers in this cluster are concerned about power structures and asymmetries shaping scientific 
research. Respondents commented on the way research funding, and the context of research more generally, is heavily influenced by politics. In particular, respondents commented on the role of research funding shaping research directions in ways that might not be the most meaningful or relevant to societal transformations.

[Funding decisions] tie science to the currently dominant and fashionable perspectives in society [which] risks damaging the value of science for the longer run.

Moreover, respondents in this cluster believe that it is their responsibility as researchers to enable the participation of societal actors in scientific research. Respondents commented in particular on the need to encourage and enable the participation of actors that are less commonly heard and represented in sustainability debates and processes of change. Finally, respondents in this cluster most strongly agree that the value of lay and practitioner knowledge in addressing sustainability problems is often underestimated. The statement that only knowledge produced by the scientific method can provide an objective perspective on the situation at hand is strongly dismissed.

Altogether, this cluster is characterized by strong overall agreement with the notion of scientists as political actors engaged in the process of shaping and changing society. Respondents perceive the domains of science and politics as blurred and identify important implications for the practice of sustainability research.

\subsubsection{Cluster 3: Responsibility for rigorous science}

Although the 44 respondents in the third cluster generally agree with the objectives of transformative research for sustainability, agreement is less strong than for the previous two clusters. In particular, respondents show reservation with respect to the responsibility of researchers for the implementation of scientific knowledge in society.

Other than in the previous two clusters, researchers in this cluster are hesitant when it comes to direct engagement with the normative and political dimension of sustainability. They stress the responsibility of researchers to do their work with 'rigour' and 'honesty'. There appear to be different views on the extent to which science can operate fully independent, yet respondents share the perspective that science cannot provide a satisfactory answer to normative and political concerns. Although scientific research can provide an important input for transformations to sustainability, discussion of norms and values, as stressed by respondents in this cluster, belong in the public sphere.

I see myself as someone who tries to do science with the highest possible rigor and honesty to inform policy, but I am neither fully independent nor political.

Science can tell us the "what is" or "how things are" but what should be or how things should be belongs in the public process of subjective, democratic deliberation (but founded on sound facts).

Engaging with extra-scientific actors is perceived as a way to make available different perspectives beyond those of the researcher. In this way, the researcher can stimulate a normative discussion, without becoming directly engaged in normative decisions herself. Researchers in this cluster are least inclined to express their own values and interest when working on contested sustainability issues.

I think the results of my research can raise awareness of the different dimensions a problem entails (social, ecological, short-vs. long term, effects for different groups of the population and different scales). It points towards the system dynamics. [However,] the implementation and specific solution/decision is up to the people acting in these socio-ecological systems.

Overall, researchers in this cluster do not see scientists as political actors. Rather, they stress the value of scientific knowledge to inform normative discussion and political debates, while researchers themselves should strive for rigour, honesty and impartiality to the largest extent possible.

\subsubsection{Cluster 4: Humility on solutions potential}

The 48 respondents in this fourth and final cluster generally agree with the objectives of transformative sustainability research, but, as for cluster three, they express multiple concerns. In particular, what stands out for this cluster is the perspective that scientists should be humble about the capacity of research to provide solutions for sustainability challenges. Some respondents shared the concern that they lack the necessary skills, time, training or experience to contribute directly to sustainability solutions. Others point out that scientists have no special privileged position when it comes to making societal decisions about how to resolve sustainability problems.

Science is one form of knowledge, that is occasionally useful; with other knowledge it interacts with values and institutions in society to shape new institutions [and] guide behaviours.

I think my - and any other sustainability science contribution - can only deliver partial solutions to sustainability problems. [...] Impact - in terms of societal change/transition - cannot be traced back to single projects. It is embedded into a network of impulses, research is only one.

Respondents in this cluster agree that research on sustainability cannot operate in isolation of normative and political concerns. Similar to cluster two, respondents are conscious about the way epistemic and normative values influence not only the selection of research topics but also the research process and outcomes. Moreover, and again similar to cluster two, the importance of transparency is stressed.

Sustainability science is fundamentally normative, even if you don't recommend specific societal changes, advocating (or helping stimulate) societal change (of any form) is not neutral. Credibility comes from being transparent about the normative dimension of science, not pretending it has none.

In line with this perspective, respondents question the notion of objective knowledge and scientific facts. They stress that (scientific) solutions are always constructed, partial and political. This puts a responsibility on the researcher seeking societal change to work in partnership with other societal actors. Moreover, and consistent with the importance placed on humility, respondents in this cluster emphasize the need to recognize and value different types of knowledge contributing to sustainability. They see scientific knowledge as one among many ways of knowing and acting that are important when it comes to questions of sustainability.

[F] acts are temporary, conditional context specific beliefs that can hopefully be verified and replicated. Facts do not transcend contexts and [are] almost always partial in any decision problem.

$[\mathrm{N}]$ o science is objective; it may be more repeatable in a controlled context, but other knowledge may provide a more accurate (contextually appropriate) perspective on an issue.

Thus, respondents in this cluster emphasize the complex entanglements between scientific, normative and political concerns and value humility in the engagement of science for sustainability.

\subsection{Comparing cluster composition}

The community of sustainability researchers is diverse, including researchers at different career-levels and with different disciplinary and geographical backgrounds. How do these characteristics relate to the four identified clusters? In terms of gender, age and career level, no significant difference in cluster composition was found. This suggests that the identified clusters represent perspectives that are spread across the community rather than reflecting the views of particular groups of researchers. There are significant difference in disciplinary orientation 
Table 4

Disciplines by cluster.

\begin{tabular}{|c|c|c|c|c|c|c|c|c|c|c|}
\hline & \multicolumn{10}{|c|}{ Discipline } \\
\hline & \multicolumn{2}{|c|}{$\begin{array}{l}\text { Social sciences } \\
(\mathrm{N}=77)\end{array}$} & \multicolumn{2}{|c|}{$\begin{array}{l}\text { Natural Sciences } \\
(\mathrm{N}=70)\end{array}$} & \multicolumn{2}{|c|}{$\begin{array}{l}\text { Interdisciplinary sciences } \\
(\mathrm{N}=91)\end{array}$} & \multicolumn{2}{|c|}{$\begin{array}{l}\text { Professional and applied sciences } \\
(\mathrm{N}=16)\end{array}$} & \multicolumn{2}{|c|}{$\begin{array}{l}\text { Other/missing } \\
(\mathrm{N}=30)\end{array}$} \\
\hline & $N$ & $\%$ & $N$ & $\%$ & $N$ & $\%$ & $N$ & $\%$ & $N$ & $\%$ \\
\hline Cluster 1 & 27 & $35 \%$ & 36 & $51 \%$ & 21 & $23 \%$ & 7 & $44 \%$ & 13 & $43 \%$ \\
\hline Cluster 2 & 29 & $38 \%$ & 4 & $\underline{6 \%}$ & 42 & $46 \%$ & 4 & $\underline{25 \%}$ & 9 & $30 \%$ \\
\hline Cluster 3 & 5 & $6 \%$ & 22 & $31 \%$ & 11 & $12 \%$ & 3 & $19 \%$ & 3 & $10 \%$ \\
\hline Cluster 4 & 16 & $21 \%$ & 8 & $11 \%$ & 17 & $19 \%$ & 2 & $13 \%$ & 5 & $17 \%$ \\
\hline
\end{tabular}

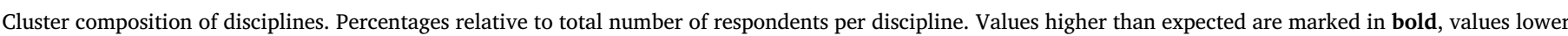
than expected are underlined (compared to equal distribution across clusters).

per clusters $\left(\chi^{2}(12)=55,24, p=<0.001\right)$. These differences are presented in Table 4 and briefly discussed below. Differences between geographical regions appeared not significant after testing for co-variance with disciplinary-orientation.

With respect to the disciplinary composition, we find that researchers in the social sciences more often share the views reflected in cluster one and two, and to a lesser extent in cluster four. Natural scientists tend to share the views of the first and third clusters, while researchers with an interdisciplinary background predominantly share the perspectives represented in the second cluster. This different orientation of researchers is perhaps not surprising and could be seen to reflect the different methodological and epistemological focus of their respective disciplinary training. The first and third cluster reflect values of scientific objectivity and neutrality, most often associated with a positivist epistemological position common in the natural sciences. The second and fourth clusters, on the other hand, acknowledge the situated character of scientific research and the deep entanglement of science and politics. Such perspectives reflect an interpretivist epistemology common in the qualitative social sciences. It is interesting to note that perspectives of interdisciplinary researchers tend to be more similar to their social sciences than their natural sciences peers. In particular, the large share of interdisciplinary researchers in the second cluster, supporting the perspective of transformative research as political act, is remarkable.

\section{Discussion}

The four clusters identified in this paper represent different perspectives on sustainability research and its normative and political dimensions. Respondents in the first cluster see the value of science in its ability to support societal change towards more sustainable futures by speaking truth to power. Respondents in the second cluster see researchers themselves as political actors engaged in shaping and changing society. Respondents in the third cluster are more hesitant when it comes to role of science as change agent for sustainability while recognizing opportunities for science to stimulate normative debates. Respondents in the fourth cluster, finally, particularly stress the complex web of actors, interests and perspectives when it comes to questions of sustainability and emphasize the need for science to be humble with respect to its societal role.

In various ways, the identified perspectives combine historically developed norms of scientific knowledge production with new perspectives on the transformative, normative and political role of sustainability research. Altogether, the results from the analysis point to some important tensions and ambiguities both within and across the identified clusters. Three interrelated tensions stand out. The first tension relates to the transformative potential of sustainability research, tension two is about the possibility and desirability of independence and impartiality, and tensions three concerns the relationship between science and politics. The next sections discuss these tensions and their relevance for current debates about transformative sustainability research.

\subsection{Transformative potential of sustainability research}

The results from this study indicate that the ideal of transformative research is widely supported among sustainability researchers. While not all researchers are comfortable with the notion of science providing solutions for sustainability challenges or becoming actively engaged in the implementation of scientific knowledge in society (in particular researchers in cluster 3), in general, sustainability researchers support these objectives. This echoes the observation of Fazey et al. (2018) that an 'opening up' of science is pertinent, where activities traditionally confined to the domain of practice, such as the implementation of scientific knowledge, are increasingly accepted as inherently entangled with scientific knowledge production.

Yet, this research also illustrates the existence of different perspectives on what transformative and solutions-oriented research entails. Some researchers (represented in cluster 2), accept the explicit involvement in societal change processes as a new role for sustainability researchers, following the model of scientists as 'change agents' (Miller, 2013; Wittmayer and Schäpke, 2014). For other researchers (represented in cluster 1 ), the ideal of the neutral, reflective scientist transferring knowledge to policy makers remains the core model of the relationship between science and societal change (Pregernig and Böcher, 2012). Yet another group of sustainability researchers emphasize the way science interacts with other institutions in affecting societal change, while rejecting a privileged position of researchers in shaping sustainability solutions (represented in cluster 4). Thus, even though the ideal of transformative research for societal change is broadly supported, sustainability researchers give shape to this ideal in profoundly different ways. Whereas the literature on transformative and solutions-oriented research stresses the necessity to transcend current patterns and practices of scientific knowledge production and seek new societal roles (Fazey et al., 2018; Wittmayer and Schäpke, 2014), such changes are not always acknowledged in perspectives on solutions-oriented sustainability research.

\subsection{Possibility and desirability of independence and impartiality}

Second, what stands out from this analysis are tensions around the importance that researchers place on principles of independence and impartiality when engaging with value-laden and contested issues of sustainability. Miller (2013) describes the 'normative limitation' of sustainability research as "its potential inability to recognize the degree to which supposedly value-free science is in fact value-laden and how scientific analyses can influence necessary and important political debates in society in complex ways" (Miller, 2013). Also other studies have pointed to the lack of awareness among sustainability researchers of the normative and political dimensions of their work (Wittmayer and Schäpke, 2014; Rosendahl et al., 2015). At first sight, findings from this research appear to be in contrast with those observations. The analysis reveals that researchers generally acknowledge the multiple external, epistemic and personal factors shaping scientific research and shows 
that there is strong agreement that it is important to be transparent about these pertinent factors of sustainability research.

Yet, perspectives differ with respect to the desirability of impartiality and independence. Some researchers perceive it as not only impossible but also undesirable to separate normative and value-laden questions from sustainability research (represented in cluster 2 and 4). They stress the importance to act on scientific knowledge about major and urgent sustainability challenges and find that in doing so, science cannot keep an impartial position but rather becomes directly engaged in normative and political processes of shaping sustainable futures. Others, however, claim that researchers should strive for independence and impartiality to the greatest extent possible (represented in cluster 1 and 3). Although full independence or complete impartiality are generally considered impossible, far from all sustainability researchers are willing to "actively acknowledge and build normative aspects into research programmes" (Fazey et al., 2018: p.63). Instead, the 'myth' of scientific objectivity and associated political neutrality continues to receive support (Milkoreit et al., 2015).

\subsection{Idealized separation between science and politics}

Finally, tensions exist with regard to the relationship between science and politics in sustainability research. This study identified a subset of sustainability researchers that embrace the political power of scientific knowledge and its ability to advance societal change (represented in cluster 2 in particular, cf. Milkoreit et al., 2015). At the same time, the findings reveal some deeply entrenched ideas about the appropriate relationship between science and politics. In particular, the notions of 'being policy relevant but not prescriptive' and 'speaking truth to power' are strongly supported by sustainability researchers. In essence, both these notions draw a boundary between what is considered 'scientific' and what is considered 'political'. An increasing body of scholarship points out that such a separation cannot be upheld in practice, especially when it comes to complex and value-laden issues of sustainability (Braun and Kropp, 2010; Turnhout et al., 2016). This separation also appears at odds with the overall response to the survey which indicates that most sustainability researchers recognize the relationship between science and politics as considerably more complex. It is thus puzzling why the idealized distinction between science and politics, or truth and power, as implied by the before mentioned statements, remains to receive such strong support. One possible explanation could be the prominence of above-mentioned perspectives in discourses of scientific assessment bodies such as the IPCC (Fazey et al., 2018). The strong support for these statements raises questions of how researchers might bring these idealized notions into practice in different ways in relation to the perspective they hold on transformative sustainability research.

\subsection{Limitations and directions for further research}

This study has several limitations that deserve to be mentioned. First, the study is based on a non-representative sample of respondents. Although considerable effort was made to reach a diverse set of researchers engaged in Future Earth, it is likely that researchers that are more concerned about the issues covered in this survey were more inclined to participate. This might have resulted in an overrepresentation of more outspoken perspectives on transformative sustainability research and its normative and political dimensions. At the same time, the survey did receive responses from researchers with different disciplinary and topical backgrounds and at different career levels, making it possible to draw careful conclusions about the way perspectives are spread across the community, although the results of the statistical tests need to be interpreted with caution. A related issue is that the survey was only available in English. This might have discouraged non-native English speaking researchers to participate and might also have caused issues with the interpretation of questions and statements. Within the sample of survey respondents, certain geographical regions are more strongly represented than others. Although this is consisted with the research community engaged in Future Earth, the lower number of responses for certain regions made it difficult to draw clear conclusions about geographical differences. The link between national, institutional and political cultures and researchers' perspectives on transformative research is an important avenue for further research.

Second, the survey approach necessarily reduces complexity. Multifaceted normative and political questions had to be translated to simple statements that could be included in the survey format. As explained in the methodology, the reason for doing so was to gain insight in the different perspectives across a large and diverse community of researchers. At the same time, it should be realised that important nuances are inevitably lost in the process. Respondents were asked to provide a single response to statements that they might value differently depending on situation and context. Moreover, The specific formulation of statements might have elicited a certain response. Complementing the quantitative analysis of survey date with qualitative analysis of written responses allowed for interpretation of the differences and tensions across the identified perspectives. However, further in-depth qualitative research is needed to better understand the meaning of these differences and tensions in the way sustainability research perceive the normative and political dimensions of their work.

Finally, the three identified tensions highlight important dimensions for further research. In particular, the study raises questions of how the identified perspectives and tensions relate to actual research practices and outcomes. What does it mean for researchers to incorporate normative and political dimensions in their research practices? How do sustainability researchers give shape to different societal roles in correspondence with their beliefs about the appropriate relationship between science and politics? And in what way are different perspectives and practices enabled or constraint by the social, institutional and political context in which researchers work? Moreover, it raises questions of the competencies and skills that sustainability researchers need in order to openly, honestly and effectively engage with value-laden and political questions of sustainability. And finally, the question emerges how such openness and reflexivity can be supported institutionally, both within local institutions and global research networks.

\section{Conclusion}

This study set out to make explicit the normative and political dimension of sustainability research and investigate the attitudes of sustainability researchers towards these dimensions of their profession. There is no single answer to the question how sustainability researchers can and should engage with the values and politics inherent to societal transformations to sustainability. It is clear, though, that this question can no longer be ignored. The ideal of global sustainability is filled with normative and political choices concerning possible and desirable futures as well as the pathways to get there (Patterson et al., 2016, 2017). With sustainability research taking an increasingly active and explicitly interventionist perspective on achieving sustainable futures, questions of values and politics thus become an inevitable component of research. Ignoring such dimensions restricts the ability of sustainability research to make a meaningful contribution to society. Moreover, failing to recognize questions of values and politics brings along the very real risk of research "unintentionally reproducing unfavourable market settings, social inequalities and exploitive institutional relations" (Fazey et al., 2018: pp. 63). Only when conversations about values and politics become a central part of the everyday practice of sustainability researcher can we expect a meaningful and reflexive contribution of science to sustainability transformations. This requires not only commitment from individual researchers but also institutional support. There is a clear opportunity for research networks such as Future Earth to explicitly address questions of values and politics and support deliberation on the roles of science in transformations to sustainability. 


\section{Acknowledgements}

I wish to thank all survey respondents for taking the time to share their views on the challenging topic of values and politics in sustainability research. I am also grateful to the Future Earth secretariat for their support in distributing the survey, and for participants at the Future Earth meeting in Bern, Switserland, 2016 for their comments on an earlier version of the survey questions. My colleagues at the Copernicus Institute of Sustainable Development, Utrecht University and the members of the School for the Future of Innovation in Society at Arizona State University provided insightful comments on an earlier draft of this paper. Furthermore, I am indebted to three anonymous reviewers for careful reading of the manuscript and helpful suggestions that helped me to improve the paper. This project was supported by a grant from the Netherlands Organization for Scientific Research (NWO) as part of the Graduate Programme on "Complex dynamics in humanenvironment systems" (grant no. 022.003.009).

\section{References}

Anderson, M.W., Teisl, M.F., Noblet, C.L., 2016. Whose values count: is a theory of social choice for sustainability science possible? Sustain. Sci. 11, 373-383. https://doi.org/ 10.1007/s11625-015-0345-1.

Barr, S., Shaw, G., Coles, T., 2011. Times for (Un)sustainability? Challenges and opportunities for developing behaviour change policy. A case-study of consumers at home and away. Glob. Environ. Change 21, 1234-1244. https://doi.org/10.1016/j. gloenvcha.2011.07.011.

Belmont Forum, ICSU, ISSC, 2011. Towards a 10 year Earth System Research initiative for Global Sustainability: A joint statement of intent from the Belmont Forum, ICSU and the ISSC. 30GA/8.5. Retrieved from:. http://www.icsu.org/future-earth/mediacentre/relevant_publications/JointStatementMay2011.pdf.

Berker, T., Bharathi, K., 2012. Energy and buildings research: challenges from the new production of knowledge. Build. Res. Inf. 40 (4), 473-480.

Braun, K., Kropp, C., 2010. Beyond speaking truth? Institutional responses to uncertainty in scientific governance. Sci. Technol. Human Values 35, 771-782. https://doi.org/ 10.1177/0162243909357916.

Caniglia, G., Schäpke, N., Lang, D.J., Abson, D.J., Luederitz, C., Wiek, A., Laubichler, M.D., Gralla, F., von Wehrden, H., 2017. Experiments and evidence in sustainability science: a typology. J. Clean. Prod. https://doi.org/10.1016/j.jclepro.2017.05.164.

Clark, W.C., van Kerkhoff, L., Lebel, L., Gallopin, G.C., 2016. Crafting usable knowledge for sustainable development. Proc. Natl. Acad. Sci. 113, 4570-4578. https://doi.org/ 10.1073/pnas.1601266113.

Cornell, S., Berkhout, F., Tuinstra, W., Tàbara, J.D., Jäger, J., Chabay, I., de Wit, B., Langlais, R., Mills, D., Moll, P., Otto, I.M., Petersen, A., Pohl, C., van Kerkhoff, L.E., 2013. Opening up knowledge systems for better responses to global environmental change. Environ. Sci. Policy 28, 60-70. https://doi.org/10.1016/j.envsci.2012.11. 008.

De Pryck, K., Wanneau, K., 2017. (Anti)-boundary work in global environmental change research and assessment. Environ. Sci. Policy 77, 203-210. https://doi.org/10.1016/ j.envsci.2017.03.012.

De Witt, A., de Boer, J., Hedlund, N., Osseweijer, P., 2016. A new tool to map the major worldviews in the Netherlands and USA, and explore how they relate to climate change. Environ. Sci. Policy 63, 101-112. https://doi.org/10.1016/j.envsci.2016.05. 012.

Demeritt, D., 2001. The construction of global warming and the politics of science. Ann. Assoc. Am. Geogr. 91, 37-41. https://doi.org/10.1111/0004-5608.00245.

European Science Foundation, 2012. Responses to Environmental and Societal Challenges for our Unstable Earth (RESCUE). ESF-COST "Frontier of Science" Joint Initiative. European Science Foundation, Strasbourg (FR) and European Cooperation in Science and Technology, Brussels (BE).

Fazey, I., Bunse, L., Msika, J., Pinke, M., Preedy, K., Evely, A.C., Lambert, E., Hastings, E., Morris, S., Reed, M.S., 2014. Evaluating knowledge exchange in interdisciplinary and multi-stakeholder research. Glob. Environ. Change 25, 204-220. https://doi.org/10. 1016/j.gloenvcha.2013.12.012.

Fazey, I., Schäpke, N., Caniglia, G., Patterson, J., Hultman, J., van Mierlo, B., Säwe, F., Wiek, A., Wittmayer, J., Aldunce, P., Al Waer, H., Battacharya, N., Bradbury, H., Carmen, E., Colvin, J., Cvitanovic, C., D'Souza, M., Gopel, M., Goldstein, B., Hämäläinen, T., Harper, G., Henfry, T., Hodgson, A., Howden, M.S., Kerr, A., Klaes, M., Lyon, C., Midgley, G., Moser, S., Mukherjee, N., Müller, K., O’Brien, K., O'Connell, D.A., Olsson, P., Page, G., Reed, M.S., Searle, B., Silvestri, G., Spaiser, V., Strasser, T., Tschakert, P., Uribe-Calvo, N., Waddell, S., Rao-Williams, J., Wise, R., Wolstenholme, R., Woods, M., Wyborn, C., 2018. Ten essentials for action-oriented and second order energy transitions, transformations and climate change research. Energy Res. Soc. Sci. 40, 54-70. https://doi.org/10.1016/j.erss.2017.11.026.

Feola, G., Nunes, R., 2014. Success and failure of grassroots innovations for addressing climate change: the case of the transition movement. Glob. Environ. Change 24, 232-250. https://doi.org/10.1016/j.gloenvcha.2013.11.011.

Funtowicz, S., Ravetz, R., 1993. Science for the post-normal age. Futures 25, 739-755. https://doi.org/10.1016/0016-3287(93)90022-L.

Future Earth, 2014. Future Earth 2025 Vision. International Council for Science (ICSU),
Paris, France.

Graham, S., Barnett, J., Fincher, R., Hurlimann, A., Mortreux, C., 2014. Local values for fairer adaptation to sea-level rise: A typology of residents and their lived values in Lakes Entrance, Australia. Glob. Environ. Change 29, 41-52. https://doi.org/10 1016/j.gloenvcha.2014.07.013.

Hoppe, R., 2009. Scientific advice and public policy: expert advisers' and policymakers' discourses on boundary work. Poiesis und Prax. 6, 235-263. https://doi.org/10. 1007/s10202-008-0053-3.

Jahn, T., Bergmann, M., Keil, F., 2012. Transdisciplinarity: between mainstreaming and marginalization. Ecol. Econ. 79, 1-10. https://doi.org/10.1016/j.ecolecon.2012.04. 017.

Jerneck, A., Olsson, L., Ness, B., Anderberg, S., Baier, M., Clark, E., Hickler, T., Hornborg, A., Kronsell, A., Lövbrand, E., Persson, J., 2011. Structuring sustainability science. Sustain. Sci. 6, 69-82. https://doi.org/10.1007/s11625-010-0117-x.

Kläy, A., Zimmermann, A.B., Schneider, F., 2015. Rethinking science for sustainable development: reflexive interaction for a paradigm transformation. Futures 65, 72-85. https://doi.org/10.1016/j.futures.2014.10.012.

Klein, J.T., 2014. Discourses of transdisciplinarity: looking back to the future. Futures 63 , 68-74. https://doi.org/10.1016/j.futures.2014.08.008.

Kowarsch, M., Jabbour, J., 2017. Solution-oriented global environmental assessments: opportunities and challenges. Environ. Sci. Policy 1-6. https://doi.org/10.1016/j. envsci.2017.08.013.

Lacey, J., Howden, S.M., Cvitanovic, C., Dowd, A.M., 2015. Informed adaptation: ethical considerations for adaptation researchers and decision-makers. Glob. Environ. Change 32, 200-210. https://doi.org/10.1016/j.gloenvcha.2015.03.011.

Lahsen, M., 2016. Toward a Sustainable Future Earth. Sci. Technol. Human Values 41, 876-898. https://doi.org/10.1177/0162243916639728.

Lang, D.J., Wiek, A., Bergmann, M., Stauffacher, M., Martens, P., Moll, P., Swilling, M., Thomas, C.J., 2012. Transdisciplinary research in sustainability science: practice, principles, and challenges. Sustain. Sci. 7, 25-43. https://doi.org/10.1007/s11625011-0149-x.

Lövbrand, E., Stripple, J., Wiman, B., 2009. Earth system governmentality. Glob. Environ. Change 19, 7-13. https://doi.org/10.1016/j.gloenvcha.2008.10.002.

Lövbrand, E., Beck, S., Chilvers, J., Forsyth, T., Hedrén, J., Hulme, M., Lidskog, R., Vasileiadou, E., 2015. Who speaks for the future of Earth? How critical social science can extend the conversation on the Anthropocene. Glob. Environ. Change 32, 211-218. https://doi.org/10.1016/j.gloenvcha.2015.03.012.

Mauser, W., Klepper, G., Rice, M., Schmalzbauer, B.S., Hackmann, H., Leemans, R., Moore, H., 2013. Transdisciplinary global change research: the co-creation of knowledge for sustainability. Curr. Opin. Environ. Sustain. 1-12. https://doi.org/10. 1016/j. cosust.2013.07.001.

Milkoreit, M., Moore, M.L., Schoon, M., Meek, C.L., 2015. Resilience scientists as changemakers. Growing the middle ground between science and advocacy? Environ. Sci. Policy 53, 87-95. https://doi.org/10.1016/j.envsci.2014.08.003.

Miller, T.R., 2013. Constructing sustainability science: emerging perspectives and research trajectories. Sustain. Sci. 8, 279-293. https://doi.org/10.1007/s11625-012 0180-6.

Miller, C.A., Edwards, P.N., 2001. Changing the Atmosphere: Expert Knowledge and Environmental Governance. MIT Press, Cambridge, MA.

Miller, T.R., Wiek, A., Sarewitz, D., Robinson, J., Olsson, L., Kriebel, D., Loorbach, D., 2014. The future of sustainability science: a solutions-oriented research agenda. Sustain. Sci. 9, 239-246. https://doi.org/10.1007/s11625-013-0224-6.

Moser, S.C., 2016. Can science on transformation transform science? Lessons from codesign. Curr. Opin. Environ. Sustain. 20, 106-115. https://doi.org/10.1016/j.cosust. 2016.10.007.

Mukhtarov, F., 2016. Reflexivity, positionality and normativity in the ethnography of policy translation. In: Berger, T., Esguerra, A. (Eds.), World Politics in Translation Power, Relationality, and Difference in Global Cooperation. Routledge.

Nowotny, H., Scott, P., Gibbons, M., 2003. "Mode 2" revisited: the new production of knowledge. Minerva 41, 179-194.

O'Brien, K., 2011. Global environmental change II: from adaptation to deliberate transformation. Prog. Hum. Geogr. 36, 667-676. https://doi.org/10.1177/ 0309132511425767.

Österblom, H., Jouffray, J.-B., Folke, C., Rockström, J., 2017. Emergence of a global science-business initiative for ocean stewardship. Proc. Natl. Acad. Sci. 04453. https://doi.org/10.1073/pnas.1704453114.

Pasgaard, M., Van Hecken, G., Ehammer, A., Strange, N., 2017. Unfolding scientific expertise and security in the changing governance of Ecosystem Services. Geoforum. https://doi.org/10.1016/j.geoforum.2017.02.001.

Patterson, J., Schulz, K., Vervoort, J., van der Hel, S., Widerberg, O., Adler, C., Hurlbert, M., Anderton, K., Sethi, M., Barau, A., 2016. Exploring the governance and politics of transformations towards sustainability. Environ. Innov. Soc. Transit. 1-16. https:// doi.org/10.1016/j.eist.2016.09.001.

Patterson, J., Thaler, T., Hoffmann, M., Hughes, S., Oels, A., Chu, E., Mert, A., Huitema, D., Burch, S., Jordan, A., 2017. Political feasibility of $1.5^{\circ} \mathrm{C}$ societal transformations: the role of social justice. Curr. Opin. Environ. Sustain. 31, 1-9. https://doi.org/10. 1016/j.cosust.2017.11.002.

Pohl, C., Rist, S., Zimmermann, A., Fry, P., Gurung, G.S., Schneider, F., Speranza, C.I., Kiteme, B., Boillat, S.S., Serrano, E., Hadorn, G.H., Wiesmann, U., 2010. Researchers' roles in knowledge co-production: experience from sustainability research in Kenya, Switzerland, Bolivia and Nepal. Sci. Public Policy 37, 267-281. https://doi.org/10. 3152/030234210X496628.

Popa, F., Guillermin, M., Dedeurwaerdere, T., 2014. A pragmatist approach to transdisciplinarity in sustainability research: from complex systems theory to reflexive science. Futures 65, 45-56. https://doi.org/10.1016/j.futures.2014.02.002.

Pregernig, M., Böcher, M., 2012. Normative and analytical perspectives on the role of 
science and expertise in environmental governance. In: Hogl, K., Kvarda, E., Nordbeck, R., Pregernig, M. (Eds.), Environmental governance: The challenge of legitimacy and effectiveness, pp. 199-219. https://doi.org/10.4337/9781849806077. 00020. Cheltenham et al.: Edward Elgar.

Ramm, T.D., Graham, S., White, C.J., Watson, C.S., 2017. Advancing values-based approaches to climate change adaptation: a case study from Australia. Environ. Sci. Policy 76, 113-123. https://doi.org/10.1016/j.envsci.2017.06.014.

Reyes-García, V., Aceituno-Mata, L., Calvet-Mir, L., Garnatje, T., Gómez-Baggethun, E., Lastra, J.J., Ontillera, R., Parada, M., Rigat, M., Vallès, J., Vila, S., Pardo-deSantayana, M., 2014. Resilience of traditional knowledge systems: the case of agricultural knowledge in home gardens of the Iberian Peninsula. Glob. Environ. Change 24, 223-231. https://doi.org/10.1016/j.gloenvcha.2013.11.022.

Rosendahl, J., Zanella, M.A., Rist, S., Weigelt, J., 2015. Scientists' situated knowledge: strong objectivity in transdisciplinarity. Futures 65, 17-27. https://doi.org/10.1016/ j.futures.2014.10.011.

Rudd, M.A., 2015. Scientists' framing of the ocean science - policy interface. Glob. Environ. Change 33, 44-60. https://doi.org/10.1016/j.gloenvcha.2015.04.006.

Schlaile, M., Urmetzer, S., Blok, V., Andersen, A., Timmermans, J., Mueller, M., Fagerberg, J., Pyka, A., 2017. Innovation Systems for Transformations towards Sustainability? Taking the Normative Dimension Seriously. Sustainability 9, 2253. https://doi.org/10.3390/su9122253.

Schneidewind, U., Singer-Brodowski, M., Augenstein, K., Stelzer, F., 2016. Pledge for a transformative science: a conceptual framework. Wuppertal Pap. 28 ISSN 0949-5266.

Scholz, R.W., 2017. The normative dimension in Transdisciplinarity, Transition Management, and Transformation Sciences: new roles of science and universities in sustainable transitioning. Sustain 9. https://doi.org/10.3390/su9060991.

Spruijt, P., Knol, A.B., Petersen, A.C., Lebret, E., 2016. Differences in views of experts about their role in particulate matter policy advice: empirical evidence from an international expert consultation. Environ. Sci. Policy 59, 44-52. https://doi.org/10. 1016/j.envsci.2016.02.003.

Stirling, A., 2014. Emancipating transformations: from controlling'the transition'to culturing plural radical progress. In: Scoones, I., Leach, M., Newell, P. (Eds.), The Politics of Green Transformations. Pathways to Sustainability. Routledge, London, UK, pp. 54-67.

Strohschneider, P., 2014. Zur Politik der Transformativen Wissenschaft. In: Brodocz, A., Herrmann, D., Schmidt, R., Schulz, D., Wessel, J.S. (Eds.), Die Verfassung Des Politischen. Springer, Wiesbaden, Germany, pp. 175-192. https://doi.org/10.1007/ 978-3-658-04784-9.

Tschakert, P., Tuana, N., Westskog, H., Koelle, B., Afrika, A., 2016. TCHANGE: the role of values and visioning in transformation science. Curr. Opin. Environ. Sustain. 20 21-25. https://doi.org/10.1016/j.cosust.2016.04.003.

Turner, R.A., Fitzsimmons, C., Forster, J., Mahon, R., Peterson, A., Stead, S.M., 2014
Measuring good governance for complex ecosystems: perceptions of coral reef-dependent communities in the Caribbean. Glob. Environ. Change 29, 105-117. https:// doi.org/10.1016/j.gloenvcha.2014.08.004.

Turnhout, E., Hisschemöller, M., Eijsackers, H., Hisschemo, M., Eijsackers, H., Hisschemöller, M., Eijsackers, H., 2007. Ecological indicators: between the two fires of science and policy. Ecol. Indic. 7, 215-228. https://doi.org/10.1016/j.ecolind. 2005.12.003.

Turnhout, E., Hisschemöller, M., Eijsackers, H., 2008. Science in Wadden Sea policy: from accommodation to advocacy. Environ. Sci. Policy 11, 227-239. https://doi.org/10. 1016/j.envsci.2007.07.004.

Turnhout, E., Dewulf, A., Hulme, M., 2016. What does policy-relevant global environmental knowledge do? The cases of climate and biodiversity. Curr. Opin. Environ. Sustain. 18, 65-72. https://doi.org/10.1016/j.cosust.2015.09.004.

van der Hel, S., 2016. New science for global sustainability? The institutionalisation of knowledge co-production in Future Earth. Environ. Sci. Policy 61, 165-175. https:// doi.org/10.1016/j.envsci.2016.03.012.

van der Hel, S., Biermann, F., 2017. The authority of science in sustainability governance: A structured comparison of six science institutions engaged with the Sustainable Development Goals. Environ. Sci. Policy 77, 211-220. https://doi.org/10.1016/j. envsci.2017.03.008.

van Kerkhoff, L., Lebel, L., 2006. Linking knowledge and action for sustainable development. Annu. Rev. Environ. Resour. 31, 445-477. https://doi.org/10.1146/ annurev.energy.31.102405.170850.

van Kerkhoff, L.E., Lebel, L., 2015. Coproductive capacities: rethinking science-governance relations in a diverse world. Ecol. Soc. 20. https://doi.org/10.5751/ES-07188200114.

Wesselink, A., Buchanan, K.S., Georgiadou, Y., Turnhout, E., 2013. Technical knowledge, discursive spaces and politics at the science-policy interface. Environ. Sci. Policy 30, 1-9. https://doi.org/10.1016/j.envsci.2012.12.008.

West, S., 2016. Meaning and Action in Sustainability Science: Interpretive Approaches for Social-ecological Systems Research (PhD Thesis). Stockholm Universityhttps://doi. org/10.13140/RG.2.2.32127.10406.

Wiek, A., Kay, B., 2015. Learning while transforming: solution-oriented learning for urban sustainability in Phoenix Arizona. Curr. Opin. Environ. Sustain. 16, 29-36. https://doi.org/10.1016/j.cosust.2015.07.001.

Wiek, A., Farioli, F., Fukushi, K., Yarime, M., 2012. Sustainability science: bridging the gap between science and society. Sustain. Sci. 7, 1-4. https://doi.org/10.1007/ s11625-011-0154-0.

Wittmayer, J.M., Schäpke, N., 2014. Action, research and participation: roles of researchers in sustainability transitions. Sustain. Sci. 9, 483-496. https://doi.org/10. 1007/s11625-014-0258-4. 